\title{
Successful therapy of refractory erythema nodosum associated with Crohn's disease using potassium iodide
}

John K Marshall MD FRCPC, E Jan Irvine MD MSc FRCPC

\begin{abstract}
JK Marshall, EJ Irvine. Successful therapy of refractory erythema nodosum associated with Crohn's disease using potassium iodide. Can J Gastroenterol 1997;11(6):501-502. Erythema nodosum is a common extraintestinal manifestation of Crohn's disease. While mild skin involvement often responds to conservative management, severe or refractory cases may require systemic corticosteroid or immunosuppressive therapy. This report describes successful treatment of severe, refractory erythema nodosum associated with Crohn's colitis using oral potassium iodide. While the mechanism of action of this agent is poorly understood, it appears to be an effective and nontoxic therapy for Crohn's-related erythema nodosum and warrants further evaluation in a placebo controlled trial.
\end{abstract}

Key Words: Crohn's disease, Erythema nodosum, Potassium iodide

$\mathrm{E}^{\mathrm{r}}$ ythema nodosum (EN) is the most common dermatological manifestation of inflammatory bowel disease (IBD). It arises in $10 \%$ to $15 \%$ of IBD patients and is associated more frequently with Crohn's disease than with ulcerative colitis (1). We report successful therapy of severe, refractory EN with oral potassium iodide in a patient with colonic Crohn's disease.

\section{CASE PRESENTATION}

A 47-year-old female with a 25-year history of colonic Crohn's disease presented with refractory $\mathrm{EN}$ of both lower extremities. Two years previously, her colitis had been controlled poorly, with recurrent erythema nodosum and pyoderma
Réussite du traitement de l'érythème noueux réfractaire associé à la maladie de Crohn à l'aide d'iodure de potassium

RÉSUMÉ : L'érythème noueux est une manifestation extra-intestinale courante de la maladie de Crohn. Si l'atteinte cutanée légère répond souvent au traitement classique, les cas graves ou réfractaires peuvent nécessiter l'administration de corticothérapie et de traitements immunosuppressifs systémiques. Ce rapport décrit la réussite du traitement d'un érythème noueux, grave et réfractaire, associé à la colite de Crohn à l'aide d'iodure de potassium. Si le mode d'action de cet agent est mal compris, il semble agir sans toxicité dans les cas d'érythème noueux associé à la maladie de Crohn et il gagnerait à faire l'objet d'un essai contrôlé par placebo.

gangrenosum requiring oral aminosalicylates and intermittent courses of oral prednisone. A proximal deep venous thrombosis had required therapeutic anticoagulation. One year later, a severe episode of EN refractory to oral prednisone responded to oral cyclosporine. When the lesions healed, cyclosporine was tapered off. Oral azathioprine was introduced, and the dosage was increased to $1.5 \mathrm{mg} / \mathrm{kg} /$ day. Maintenance oral 5-aminosalicylic acid (3 g/day) was also administered.

Three months after the patient started taking azathioprine, the EN recurred. Her intestinal Crohn's disease was in clinical remission at the time, and colonoscopy to the terminal ileum revealed only mild colonic disease with scattered

This paper was a winning entry in the Consultations in Gastroenterology case study competition that was initiated and funded with the generous support of Astra Canada and is endorsed by the Canadian Association of Gastroenterology

Division of Gastroenterology, Department of Medicine, McMaster University, Hamilton, Ontario

Correspondence: Dr John K Marshall, Clinical Scholar, Division of Gastroenterology (4W8), McMaster University Medical Centre, 1200 Main Street West, Hamilton, Ontario L8N 325. Telephone 905-521-2100 ext 6402, fax 905-521-4958, e-mail marshllj@fhs.csu.mcmaster.ca 
aphthous ulceration. Oral prednisone $40 \mathrm{mg} /$ day was prescribed but without effect. Over the following four months, the EN became more extensive and increasingly painful. Oral cyclosporine $300 \mathrm{mg} /$ day was added to her treatment. Despite four weeks of therapy, the EN continued to worsen so the cyclosporine was tapered off. Treatment was then initiated with a saturated solution of potassium iodide at a dose of 30 drops/day (approximately $1500 \mathrm{mg}$ ).

The EN improved dramatically within two weeks and healed completely by four months, when the potassium iodide was discontinued. Twelve months later, the EN recurred and, again, it responded rapidly to a four-week course of oral potassium iodide. Four months later, the patient's colitis remains in clinical remission, and she has suffered no further recurrence of EN.

\section{DISCUSSION}

EN, which occurs in $10 \%$ to $15 \%$ of patients with IBD, is more common in patients with Crohn's disease and colonic involvement (1). Patients present with tender, red subcutaneous nodules of the lower extremities. Although the etiology of EN is unclear, biopsy typically reveals histological evidence of a septal panniculitis. While the severity of EN tends to reflect the activity of the underlying colitis, it may also occur in association with clinically quiescent disease, as was the case in our patient.

Mild EN can be treated successfully with bedrest and analgesia, along with the administration of salicylates or nonsteroidal anti-inflammatory agents. We decided to avoid these medications in our patient because of the risk of Crohn's disease exacerbation associated with their use. Although EN associated with underlying IBD usually responds to medical or surgical management of the colitis, our patient had active EN despite clinical and endoscopic remission of her Crohn's disease. Refractory or severe EN may respond to systemic corticosteroids, hydroxychloroquine or cyclosporine, but these agents often give unsatisfactory results and may also be associated with serious systemic toxicity.

Potassium iodide, although widely used for dermatological disorders in the early part of this century (2), has never been tested rigorously in a placebo controlled trial. Authors of uncontrolled reports have proposed oral iodides as treatment

\section{REFERENCES}

1. Levine JB, Lukawski-Trubish D. Extraintestinal considerations in inflammatory bowel disease. Gastroenterol Clin North Am 1995;24:633-46.

2. Kelly FC. Iodine in medicine and pharmacy since its discovery: 1811 to 1961 . Proc R Soc Med 1961;54:831-7.

3. Schulz EJ, Whiting DA. Treatment of erythema nodosum and nodular vasculitis with potassium iodide. Br J Dermatol 1976;94:75-8.

4. Horio T, Danno K, Okamoto H, Myachi Y, Imamura S. Potassium iodide in erythema nodosum and other erythematous disorders. J Am Acad Dermatol 1983;9:77-81.

5. Horio T, Imamura S, Danno K, Ofuji S. Potassium iodide in the treatment of erythema nodosum and nodular vasculitis. Arch Dermatol 1981;117:29-31.

6. Myatt AE, Baker DJ, Byfield DM. Sweet's syndrome: a report on the use of potassium iodide. Clin Exp Dermatol 1987;12:345-9.

7. Kauffman CA. Old and new therapies for sporotrichosis. Clin Infect Dis 1995;21:981-5. for nodular vasculitis (3-5), erythema multiforme (4), Sweet's syndrome (6), cutaneous sporotrichosis (7), pulmonary aspergillosis (8) and pyoderma gangrenosum (9).

The first large case series of patients treated for EN was reported by Schulz and Whiting in 1976 (3). A favourable response was observed in 24 of 28 patients given potassium iodide at a dose of 360 to $900 \mathrm{mg} /$ day. Improvement occurred at two days with complete resolution at two weeks. Horio et al (5) later treated 15 patients with EN using oral potassium iodide $900 \mathrm{mg} /$ day (5). Eleven of 15 patients responded dramatically within a few days and were healed completely by two weeks. No clinical characteristics at presentation were found to predict response. In another series, Heid et al (10) noted a rapid response in five patients with EN who were administered potassium iodide $1000 \mathrm{mg} /$ day. In each of these case series, no drug-related adverse effects were reported. Of interest, ours is the first reported case of successful potassium iodide therapy in which EN was associated with underlying IBD.

It is not known why EN responds to potassium iodide therapy. The suppression of oxygen-free radical formation (11), inhibition of leukocyte chemotaxis (12) or release of heparin from mast cell granules (13) have been hypothesized to be the putative mechanism of action.

While published case series report potassium iodide to be well tolerated, iodides have been associated with dose-related adverse effects such as nausea, a metallic taste, coryza, bronchorrhea, sialoadenitis, thryotoxicosis and 'cutaneous iodine', a pustular acneform eruption (14). Hypersensitivity reactions characterized by fever, arthralgia, asthma or eosinophilia are also described (14). Indeed, potassium iodide has been reported, paradoxically, to cause EN in some patients (15). Our patient suffered no adverse events attributable to the drug despite two courses of therapy at a relatively high dose over five months.

\section{CONCLUSIONS}

Potassium iodide shows promise as an inexpensive and relatively nontoxic therapy for patients with refractory erythema nodosum complicating IBD. Placebo controlled trials are needed to confirm its efficacy and to define more accurately its adverse effects in this population.

8. Rumbak M, Kohler G, Eastrige C, Winer-Muran H, Gavant M. Topical treatment of life threatening haemoptysis from aspergillomas. Thorax 1996;51:253-5.

9. Richardson JB, Callen JP. Pyoderma gangrenosum treated succesfully with potassium iodide. J Am Acad Dermatol 1993;28:1005-7.

10. Heid L, Truchetet F, Friedel J, Caussade P. Érythème noueux: traitement par iodure de potassium. Presse Med 1983;12:2461.

11. Miyachi Y, Niwa Y. Effects of potassium iodide, colchicine, and dapsone on the generation of polymorphonuclear leukocyte-derived oxygen intermediates. Br J Dermatol 1982;107:209-14.

12. Stone OJ, Willis CJ. Iodide enhancement of inflammation: experimental with clinical correlation. Texas Rep Biol Med 1967;25:205.

13. Cantin M. Study of generalized erythema induced by iodides. J Invest Dermatol 1967;48:560-6.

14. Horn B, Kabins SA. Iodide fever. Am J Med Sci 1972;264:467-71.

15. Zone JJ, Horio T. Potassium iodide and vasculitis. Arch Dermatol $1981 ; 117: 758-9$ 


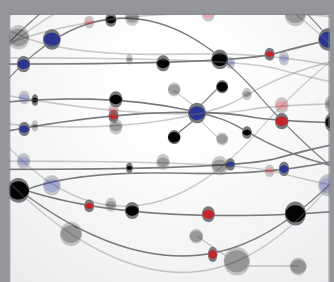

The Scientific World Journal
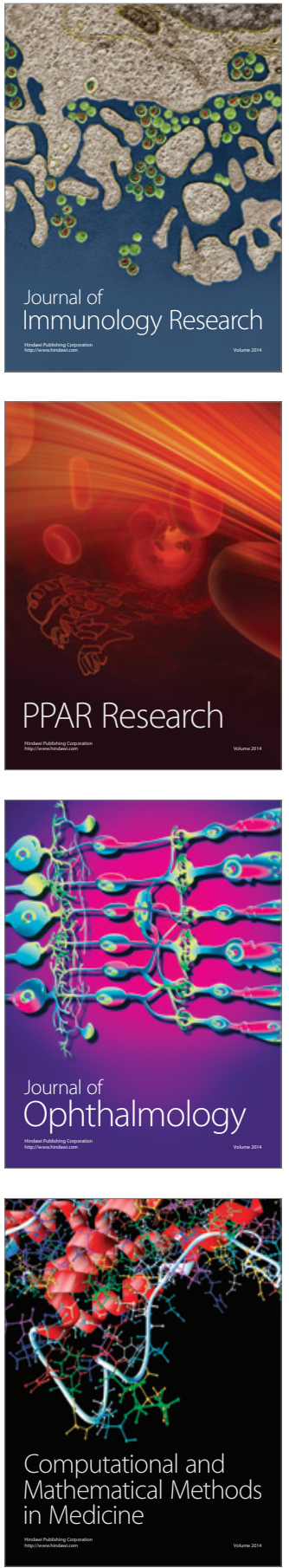

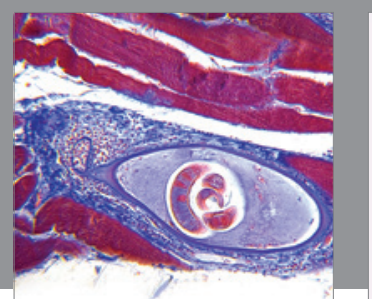

Gastroenterology Research and Practice

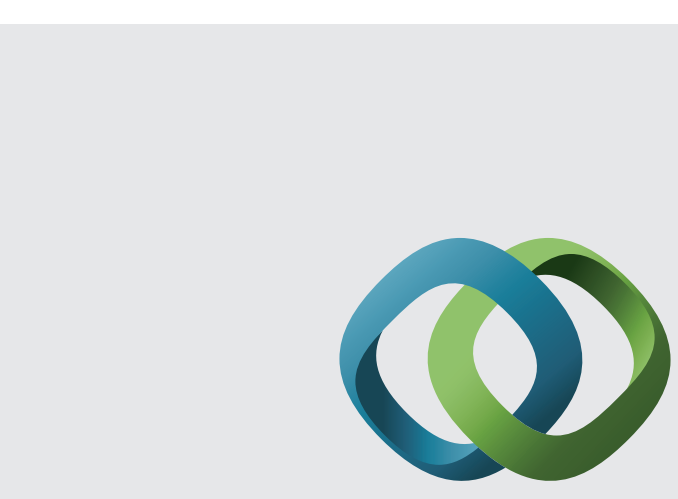

\section{Hindawi}

Submit your manuscripts at

http://www.hindawi.com
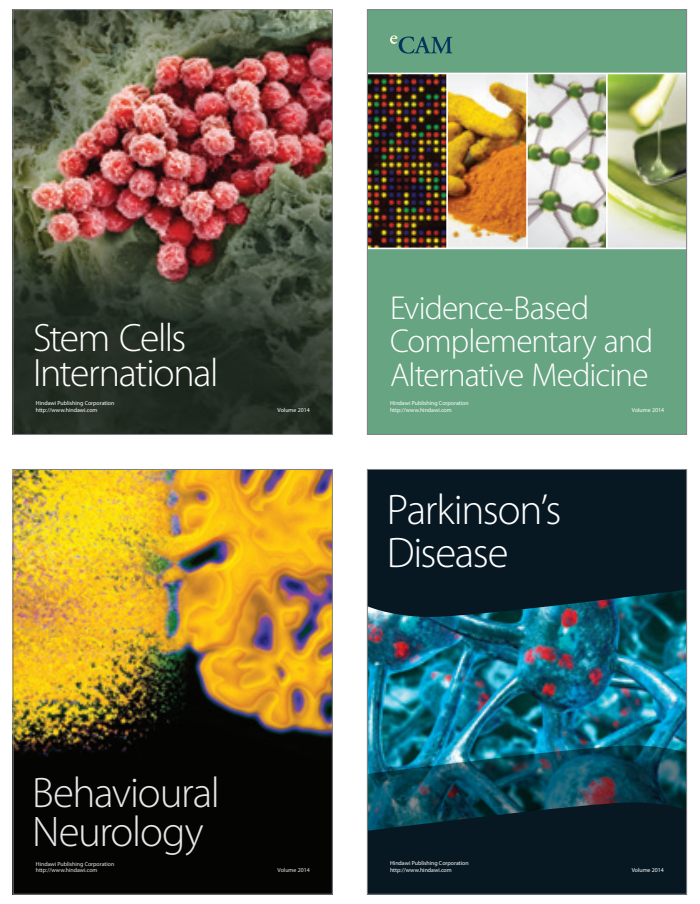
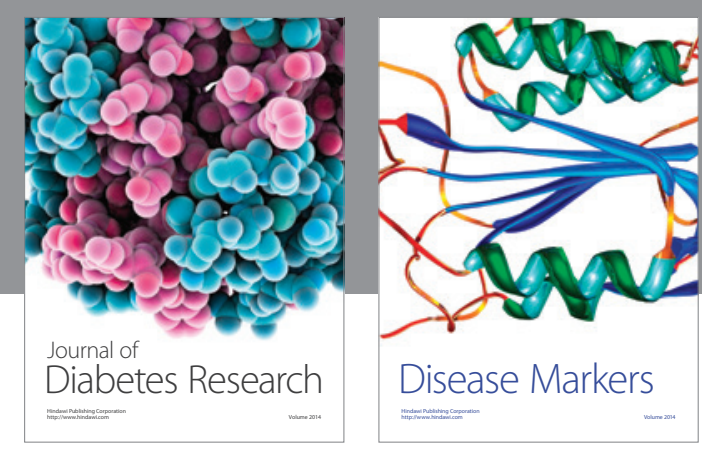

Disease Markers
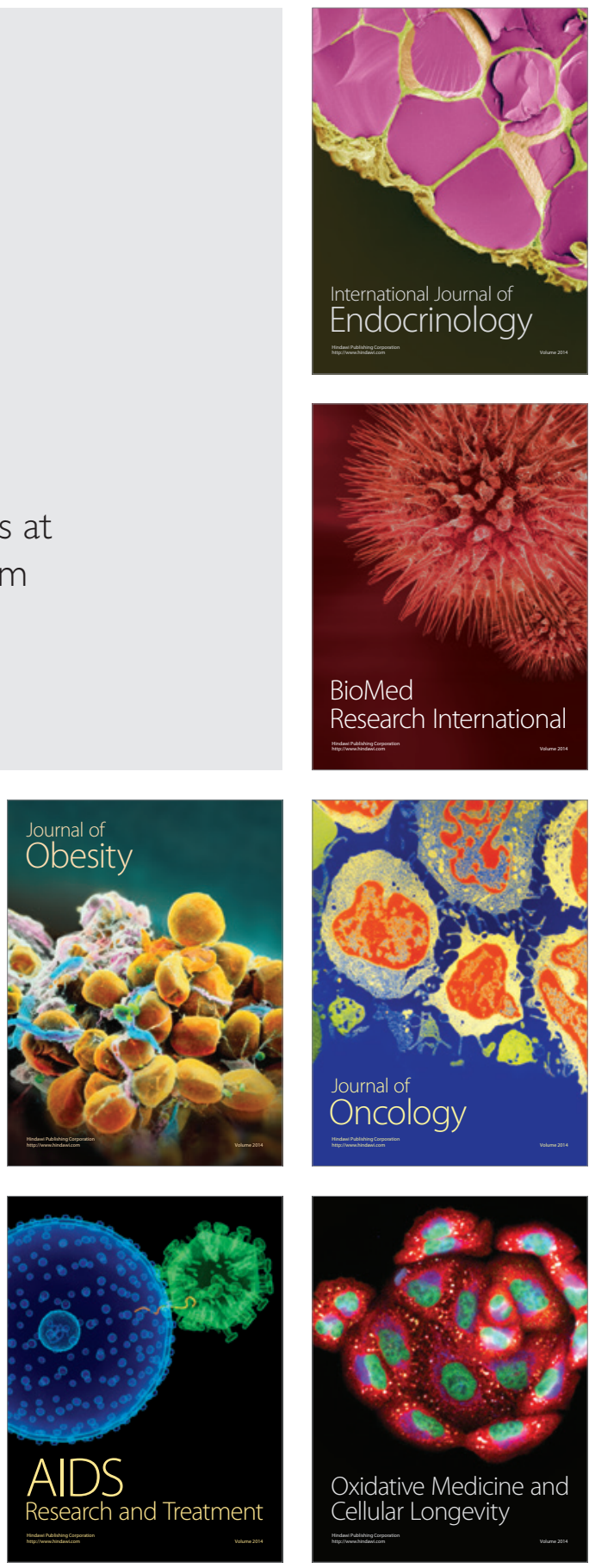